\title{
A Laminin-2, Dystroglycan, Utrophin Axis Is Required for Compartmentalization and Elongation of Myelin Segments
}

\author{
Felipe A. Court, ${ }^{1}$ Jane E. Hewitt, ${ }^{2}$ Kay Davies, ${ }^{3}$ Bruce L. Patton, ${ }^{4}$ Antonino Uncini, ${ }^{5}$ Lawrence Wrabetz, ${ }^{1}$ and \\ M. Laura Feltri ${ }^{1}$ \\ ${ }^{1}$ San Raffaele Scientific Institute, Department of Genetics and Cell Biology, 20132 Milan, Italy, ${ }^{2}$ Institute of Genetics, University of Nottingham, Nottingham \\ NG7 2UH, United Kingdom, ${ }^{3}$ Medical Research Council Functional Genomics Unit, Department of Physiology, Anatomy and Genetics, University of Oxford, \\ Oxford OX1 3QX, United Kingdom, ${ }^{4}$ Oregon Health \& Science University, Portland, Oregon 97239-3098, and 5University “G. d'Annunzio" and the \\ Degenerative Diseases Unit, Aging Research Center, Centro Studi Invecchiamento, “G. d’Annunzio” University Foundation Chieti-Pescara, I-66013 \\ Chieti, Italy
}

Animal and plant cells compartmentalize to perform morphogenetic functions. Compartmentalization of myelin-forming Schwann cells may favor elongation of myelin segments to the size required for efficient conduction of nerve impulses. Compartments in myelinated fibers were described by Ramón y Cajal and depend on periaxin, mutated in the hereditary neuropathy Charcot-Marie-Tooth disease type $4 \mathrm{~F}$ (Charcot-Marie-Tooth $4 \mathrm{~F}$ ). Lack of periaxin in mice causes loss of compartments, formation of short myelin segments (internodes) and reduced nerve conduction velocity. How compartments are formed and maintained, and their relevance to human neuropathies is largely unknown. Here we show that formation of compartments around myelin is driven by the actin cytoskeleton, and maintained by actin and tubulin fences through linkage to the dystroglycan complex. Compartmentalization and establishment of correct internodal length requires the presence of glycosylated dystroglycan, utrophin and extracellular laminin-2/211. A neuropathic patient with reduced internodal length and nerve conduction velocity because of absence of laminin-2/211 (congenital muscular dystrophy $1 \mathrm{~A}$ ) also shows abnormal compartmentalization. These data link formation of compartments through a laminin2, dystroglycan, utrophin, actin axis to internodal length, and provide a common pathogenetic mechanism for two inherited human neuropathies. Other cell types may exploit dystroglycan complexes in similar fashions to create barriers and compartments.

\section{Introduction}

Myelin is produced by oligodendrocytes in the CNS and Schwann cells in the peripheral nervous system and wraps large-caliber axons to ensure efficient transmission of nerve impulses. Whereas oligodendrocytes form many short myelin segments on several axons, Schwann cells form longer myelin segments (internodes) on a single axon (Geren and Schmitt, 1954; Bunge et al., 1962). Only Schwann cells polarize their outermost cytoplasm outside myelin in domains, first described by Ramón y Cajal (1933). This outer region is organized in two compartments: areas in which the Schwann cell membrane is closely apposed to the myelin sheath (Fig. 1, named appositions, plaques or patches,

Received Nov. 27, 2008; revised Jan. 21, 2009; accepted Jan. 24, 2009.

This work was supported by Award Numbers R01NS045630 (to M.L.F.) and R01-NS055256 (to L.W.) from the National Institute of Neurological Disorders and Stroke, Telethon Italia (Grants GGP08021 to M.L.F. and GGP071100 to L.W.), and Fondecyt, Chile (Grant 1070377 to F.A.C.). F.A.C. was supported by a European Molecular Biology Organization long-term fellowship. J.E.H. was supported by a Biotechnology and Biological Sciences Research Council Research Development Fellowship. We thank Desirée Zambroni for excellent technical contribution, Brian Popko and Eleni Levedakou (University of Chicago, Chicago, IL) for initially providing myd tissues, and Kevin Campbell (Howard Hughes Medical Institute, University of lowa, lowa City, IA) and Fumiaki Saito (Teikyo University, Tokyo, Japan) for dystroglycan floxed mice.

Correspondence should be addressed to either of the following: Maria Laura Feltri, San Raffaele Scientific Institute, via Olgettina 58, 20132 Milan, Italy, E-mail: feltri.laura@hsr.it; or Felipe A. Court, Department of Physiological Sciences, Universidad Católica de Chile, Avenida B. O'Higgins 340/Casilla 114-D Santiago, Chile, E-mail: fcourt@bio.puc.cl.

DOI:10.1523/JNEUROSCI.5672-08.2009

Copyright $\odot 2009$ Society for Neuroscience $\quad$ 0270-6474/09/293908-12\$15.00/0 red), and areas with abundant cytoplasm that forms channels traversing the internode (Fig. 1, named Cajal bands, green). It was proposed that cytoplasmic channels optimize microtubulebased transport for proper elongation of Schwann cells (Court et al., 2004). The distance between consecutive nodes of Ranvier, internodal length (IL) is occupied by a single Schwann cell and probably influences nerve conduction velocity (Brill et al., 1977; Di Muzio et al., 2003). Therefore, Schwann cells need to carefully regulate elongation together with myelin thickness, axonal diameter and lateral sealing of paranodes to efficiently conduct impulses (for review, see Sherman and Brophy, 2005).

Periaxin, mutated in Charcot-Marie-Tooth disease type $4 \mathrm{~F}$ (Charcot-Marie-Tooth 4F) (Gillespie et al., 2000; Boerkoel et al., 2001; Guilbot et al., 2001), is required for Schwann cell compartmentalization. Periaxin-null mice lack compartments and show decreased IL (Court et al., 2004). Whether formation of abnormal compartments is consistently associated with reduced IL, and whether periaxin influences IL via compartments or through other mechanisms are unknown. Periaxin associates with the dystroglycan (DG) complex (DGC) through dystrophin-related protein 2 (DRP2) (Sherman et al., 2001) the only molecule known to be restricted to the appositions/patches (Sherman et al., 2001). As in other cells, the DGC in Schwann cells links laminins in the basal lamina to intracellular proteins, through the laminin receptor $\alpha$-DG, the membrane spanning protein $\beta$-DG and intracellular proteins, including the dystrophins DRP2, utrophin 


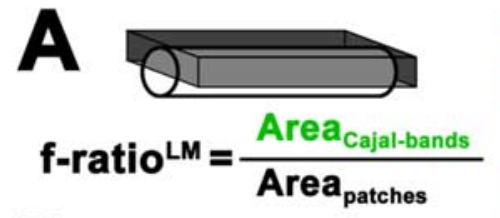

Drp2/Phalloidin

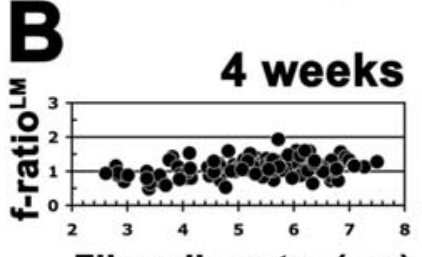

Fiber diameter $(\mu \mathrm{m})$
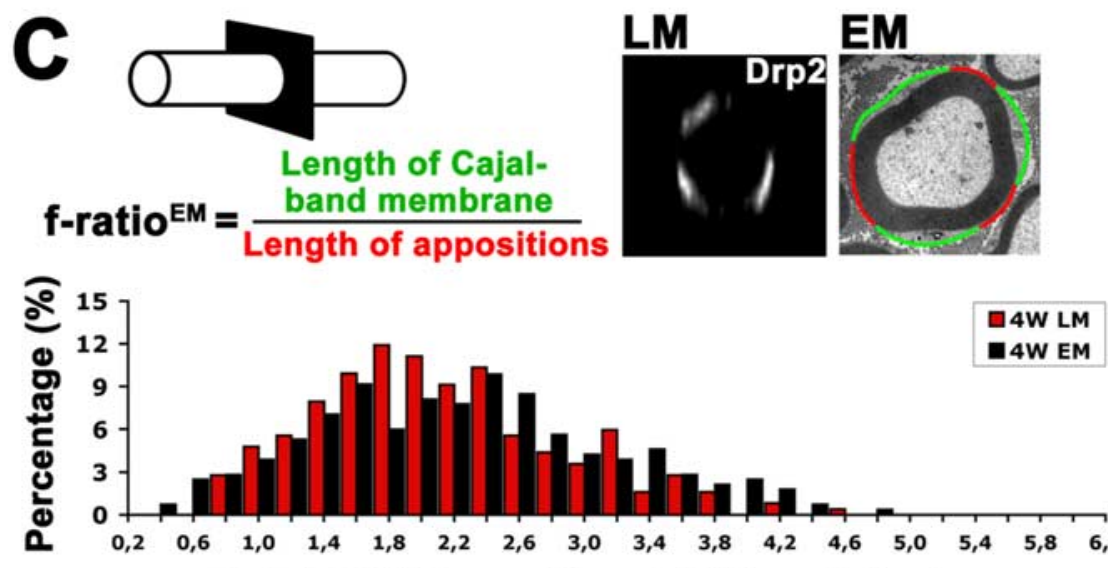

Patch (LM)/Apposition (EM) length $(\mu \mathrm{m})$

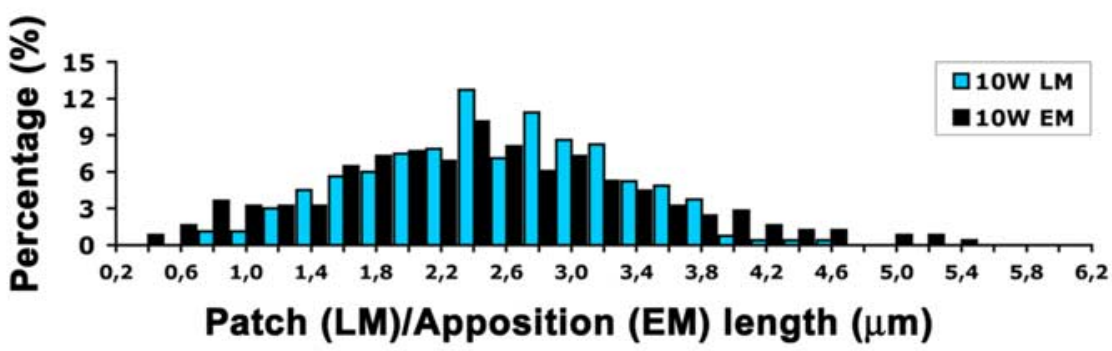

Figure 1. Schwann cell compartments at the light and electron microscopic level. $\boldsymbol{A}$, Cajal-bands and trabeculae are shown in green, whereas appositions/patches are shown in red or black. Teased fibers from mouse sciatic nerve were immunostained for DRP2 together with FITC-phalloidin. The DRP2-positive signal above an arbitrary threshold (right panel, in black) was used to calculate the ratio between (ajal bands/trabelculae and patch area, named $f$-ratio. $\boldsymbol{B}$, The $f$-ratio was calculated for $S$ chwann cells of different sizes (fiber diameter) and at different ages. After the formation of patches (between P5 and P10) the $f$-ratio reaches a value of approximately one, which is conserved among animal ages and the size of nerve fibers. $\boldsymbol{C}$, To establish that LM patches (stained with DRP2) correspond to EM appositions, the distribution of LM and EM structures were compared (method visually described in the top part of $\mathbf{C}$ ). At both 4 and 10 weeks of age, similar distributions of length were obtained (bottom graphs).

and Dp116 (Yamada et al., 1996; Saito et al., 1999; Sherman et al., 2001). Schwann cell basal lamina contains laminin-2/211 $(\alpha 2 \beta 1 \gamma 1)$ and 8/411 ( $\alpha 4 \beta 1 \gamma 1)$ (Patton et al., 1997). Absence of laminin-2/211 ( $\alpha 2$ chain mutations) in congenital muscular dystrophy 1A (MDC1A) or in the dystrophic mouse model DyDy, causes a neuropathy which also displays reduced IL (Jaros and Jenkison, 1983).

Here we show that laminin- $\alpha 2$ (but not laminin- $\alpha 4$ ), DG and its glycosylation are required for normal compartments and IL. Compartments are also impaired in the sural nerve from an MDC1A patient, in which reduced IL and conduction velocity were reported. During development filamentous actin (f-actin) first appears in territories that will become Cajal bands, and this appearance coincides with formation of appositions by electron microscopy, before DRP2 is detectable. Disruption of actin or microtubules in adult nerves allows DRP2 appositions to invade cytoplasmic spaces. Finally deletion of utrophin, the only dystrophin with an actin-binding domain, impairs compartments and reduces IL. We conclude that formation of the laminin 2-DGC-utrophin-actin linkage regulates the formation of compartments, by maintaining actin fences that dictate the localization of Cajal bands. We propose that a common pathogenetic mechanism, the disorganization of cytoplasmic compartments, underlies the reduced internodal length observed in Charcot-MarieTooth 4F and MDC1A neuropathies.

\section{Materials and Methods}

Mice. P0Cre, DG floxed, $D y^{2 j / 2 j}, m y d / m y d$, Lama4ko, and utrophin knock-out mice have been previously reported (Meier and Southard, 1970; Lane et al., 1976; Deconinck et al., 1997; Feltri et al., 1999; Thyboll et al., 2002; Saito et al., 2003). Experiments with animals followed protocols approved by the Institutional Animal Care and Use Committees of our institutes.

Immunohistochemistry (on teased fibers) and electron microscopy. For immunofluorescence analysis, sciatic nerve fibers from a minimum of 3 mice for each genotype were dissected and immersion fixed in $4 \%$ paraformaldehyde in $0.1 \mathrm{~m}$ phosphate buffer saline (PBS, $\mathrm{pH} 7.4$ ) for $45 \mathrm{~min}$. After washing in PBS, the perineurium was dissected and nerve bundles were separated using a pair of acupuncture needles. Nerve bundles were blocked/permeabilized with $0,1 \%$ Triton X-100, 5\% fish skin gelatin (Sigma) in PBS for $1 \mathrm{~h}$ at room temperature. First antibodies were applied in the same blocking/permeabilizing solution overnight at $4^{\circ} \mathrm{C}$. Subsequently, fibers were washed in PBS with $0,1 \%$ Triton X-100. Secondary antibodies were applied in blocking/permeabilizing solution for $3 \mathrm{~h}$ at room temperature. After washing in PBS, single nerve fibers were teased in Silane-treated slides in a drop of PBS using a pair of acupuncture needles, excess PBS was removed and fibers were mounted in Vectashield (Vector Laboratories). A spinning Nipkow disk confocal microscope (UltraVIEW, Perkin-Elmer) was used for imaging. For electron microscopy, sciatic nerves were dissected and immersion fixed in $2 \%$ glutaraldehyde in $0.1 \mathrm{M}$ phosphate buffer, $\mathrm{pH} 7.4$ overnight at $4^{\circ} \mathrm{C}$ and processed as previously described (Wrabetz et al., 2000).

Primary/secondary antibodies and dyes. The following antibodies and dyes, sources and dilution were used. Rabbit anti-DRP2 (gift from P. J. Brophy, University of Edinburgh, Edinburgh, UK; 1:200), Mouse antitubulin (Sigma, 1:500), FITC and rhodamine-conjugated phallodin (Sigma, 1:400). Goat anti-rabbit FITC (Jackson Immunoresearch, 1:400), Goat anti-rabbit tetramethylrhodamine isothiocyanate (Jackson Immunoresearch, 1:400), goat anti-mouse Cy5 (Jackson Immunoresearch, 1:400), 4' '6' -diamidino-2-phenylindole dihydrochloride (DAPI) (Sigma, $4 \mu \mathrm{g} / \mathrm{ml}$ ).

Drug injection. Intraperineural drug injection was performed as previously described (Court and Alvarez, 2000). Briefly, animals were anes- 
thetized with Avertin ( $0.37 \mathrm{mg} / \mathrm{gram})$ and the sciatic nerve was exposed; a small hole was made in the perineurium using a tuberculin syringeneedle and $3 \mu \mathrm{l}$ of cytoskeleton depolymerizing drugs were slowly injected intraperineurally using a $10 \mu \mathrm{l}$ Hamilton syringe fitted with a $34 \mathrm{G}$ needle, the wound was closed using surgical clips. The following drug concentrations were used: colchicine, $2 \mathrm{mg} / \mathrm{ml}$ (Sigma); cytochalasin-D, $2 \mu \mathrm{g} / \mathrm{ml}$ (Sigma). After $1 \mathrm{~d}$ of drug infiltration, the nerves were processed for immunofluorescence analysis as described above.

Morphological analysis and f-ratio. For $f$-ratio analysis at the electronmicroscopic (EM) level, random micrographs of nerve transverse sections were taken at the electron microscope, and the lengths of appositions and cytoplasmic regions of myelin-forming Schwann cells (Fig. 1C) were measured using the software ImageJ; in addition, fiber diameters were estimated from fiber area measurements. At the light-microscopic (LM) level, calibrated confocal images of the complete Schwann cell volume immunostained with antibodies against DRP2 and counterstained with FITC-phalloidin were obtained, and Z-projections of the complete longitudinal half of the cell were performed (supplemental Fig. 1 , available at www.jneurosci.org as supplemental material). The other half of the fiber was projected and analyzed separately, to avoid merging of planes on different sides of the nucleus. Using this method, patches do not have to be completely in the half projection, and if they extend beyond the other half of the fiber each part of the split patch belong to the corresponding half projection. Schwann cells were randomly selected avoiding both nuclei and nodal regions were appositions are absent. A length of $\sim 130 \mu \mathrm{m}$ was imaged for each Z-projection and at least 20 fibers from 3 animals were analyzed. Using ImageJ, the DRP2 staining (after RGB color split) was adjusted using the threshold function of ImageJ. The threshold (in black and white) was set arbitrarily for each image, to match most closely the size and shape of patches (Fig. $1 \mathrm{~A}$, bottom image; supplemental Fig. 1, available at www.jneurosci.org as supplemental material; indicated as "after threshold"). Because DRP2 patches have very defined edges, using a different threshold for each image did not add significant errors, but it was necessary because of differences in overall DRP2 staining intensities among patches and among samples processed at different times. After setting the threshold, the area occupied by the DRP2 signal was measured using the "Analyze particles" routine of ImageJ (with settings: minimum pixel $=4.5 \mu \mathrm{m}$, show outline, exclude holes, flood fill; see automated measurement of patch area, PA, supplemental Fig. 1, available at www.jneurosci.org as supplemental material). Open cytoplasmic regions (Cajal bands and trabeculae) were estimated by measuring the whole Schwann cell area and subtracting the corresponding DRP2 patches area (supplemental Fig. 1, available at www.jneurosci.org as supplemental material, manual measurement of total fiber area, TA). Therefore, the Cajal bands/trabeculae area is defined as the Schwann cell compartment lacking DRP2 staining. In addition, fiber diameters were measured for each case. For length $(\operatorname{arc})$ measurements of DRP2 ${ }^{+}$patches (Fig. $1 C, \mathrm{LM}$ ), Z-projections were randomly performed along the nerve fibers stained as above and measured using ImageJ. Numerical operations were later performed using Excel. For internodal length measurements, myelinated nerve fibers were taken from sciatic nerves, stained with rhodamine-conjugated phalloidin and DAPI, teased as described above and imaged with a fluorescence microscope. The length between two nodes of Ranvier was measured using ImageJ as previously described (Court et al., 2004). At the EM level, the $f$-ratio was higher when comparing to the $\operatorname{LM} f$-ratio value. This discrepancy can be explained by the different projections used. At the LM level, we project and measure the area of the surface of one side of the Schwann cell, in contrast the EM measurements were taken in single crosssections, measuring the length of the membrane corresponding to cytoplasm and appositions; because these were random cross-section, they can pass in the perinuclear region or at the level of transverse bands or trabeculae that will show a higher amount of cytoplasm. Importantly, when the distribution of apposition lengths at the EM level was compared with a similar analysis done in confocal Z-projection of DRP2 labeled fibers (Fig. 1C), the distributions matched in Schwann cells from wild-type (Fig. 1C) and mutant animals (see Fig. $6 B$ ) showing abnormal cytoplasmic compartmentalization, validating the analysis at both LM and EM levels.
Human biopsy. Sural nerve biopsies from an MDC1A patient and from a patient with an unrelated, acquired inflammatory neuropathy was obtained as described previously (Di Muzio et al., 2003), in accordance with protocols approved by institutional ethical committees. Immunohistochemistry on the MDC1A nerve showed absence of laminin-2 (Di Muzio et al., 2003).

\section{Results}

\section{Compartmentalization analysis of myelinated nerve fibers}

The outer (abaxonal) Schwann cell cytoplasm alternates longitudinal channels (Cajal bands) and transverse domains (trabeculae), where most cytoplasmic proteins reside, with cytoplasmicpoor areas (appearing as appositions in electron microscopy, and plaques/patches by immunostaining), where only DRP2 has been described (Sherman et al., 2001; Albrecht et al., 2008). To quantify this organization we stained plaques/patches in isolated myelinated fibers from mouse sciatic nerves using antibody against DRP2, and Cajal bands and trabeculae using FITC-conjugated phalloidin to reveal the actin cytoskeleton (Fig. $1 \mathrm{~A}$ ). Confocal Z-stacks projections spanning half of the fiber were used to select the DRP2 that fell above an arbitrary threshold. From the resulting images, we calculated a ratio between the cytoplasmic rich Cajal band areas (F-actin signal) and the DRP2 ${ }^{+}$patches area and named it $f$-ratio (Fig. $1 A$ ). In mature nerves the $f$-ratio is $\sim 1$ (Fig. $1 B$ ) indicating that the outer cytoplasm contains approximately the same amount of "open" and "apposed" cytoplasm.

The $f$-ratio was conserved across fiber diameters and ages (Fig. $1 B$ ) making it a useful tool to study cytoplasmic compartmentalization in Schwann cells independently of fiber caliber. During development, compartmentalization of the Schwann cell cytoplasm begins after myelin compaction, between postnatal day 5 (P5) and P10 (Court, 2004). At this time, almost no cytoplasmic appositions had been formed (see below), so the $f$-ratio was significantly higher (Fig. $1 B$ ).

At the ultrastructural level, appositions are domains in which the plasma membrane makes close contact to the outermost layer of the myelin sheath (Fig. $1 C$, red). To demonstrate that DRP2 ${ }^{+}$ patches at the LM level represent appositions, we compared the length of the plasma membrane arcs above transversal projections of DRP2 ${ }^{+}$patches (Fig. $1 C, \mathrm{LM}$ ) with the length of appositions measured from electron microscopical cross-sections of nerve fibers (Fig. 1C, EM). The distribution of lengths of random $\mathrm{DRP}_{2}{ }^{+}$patches and of appositions were comparable (Fig. 1C, bottom graphs), strongly suggesting that $\mathrm{DRP} 2^{+}$patches are the LM correlate of EM appositions in mature nerves, and validating the $f$-ratio calculation. Measurement of appositions at the ultrastructural level provides a useful method to calculate the cytoplasmic compartmentalization in samples processed for electron microscopy.

\section{Formation of appositions}

As shown, cytoplasmic channels/Cajal bands contain actin whereas regions devoid of cytoplasm (LM patches, EM appositions) contain DRP2. To ask which of these two regions form first during development, we stained nerve fibers from P5 and P10 wild-type (WT) mice as before. At P5, Schwann cells present a homogenous pattern of F-actin expression with no compartmentalization (Fig. 2A). We detected low levels of DRP2, mainly in perinuclear areas (Fig. 2A). Consistent with the idea that DRP2 localization correspond to appositions, by electron microscopy, P5 nerve fibers with thin but compacted myelin were surrounded by a concentric ring of cytoplasm with no appositions (Fig. $2 \mathrm{~B}$ ). In P10 Schwann cells, the pattern of F-actin changed dramati- 

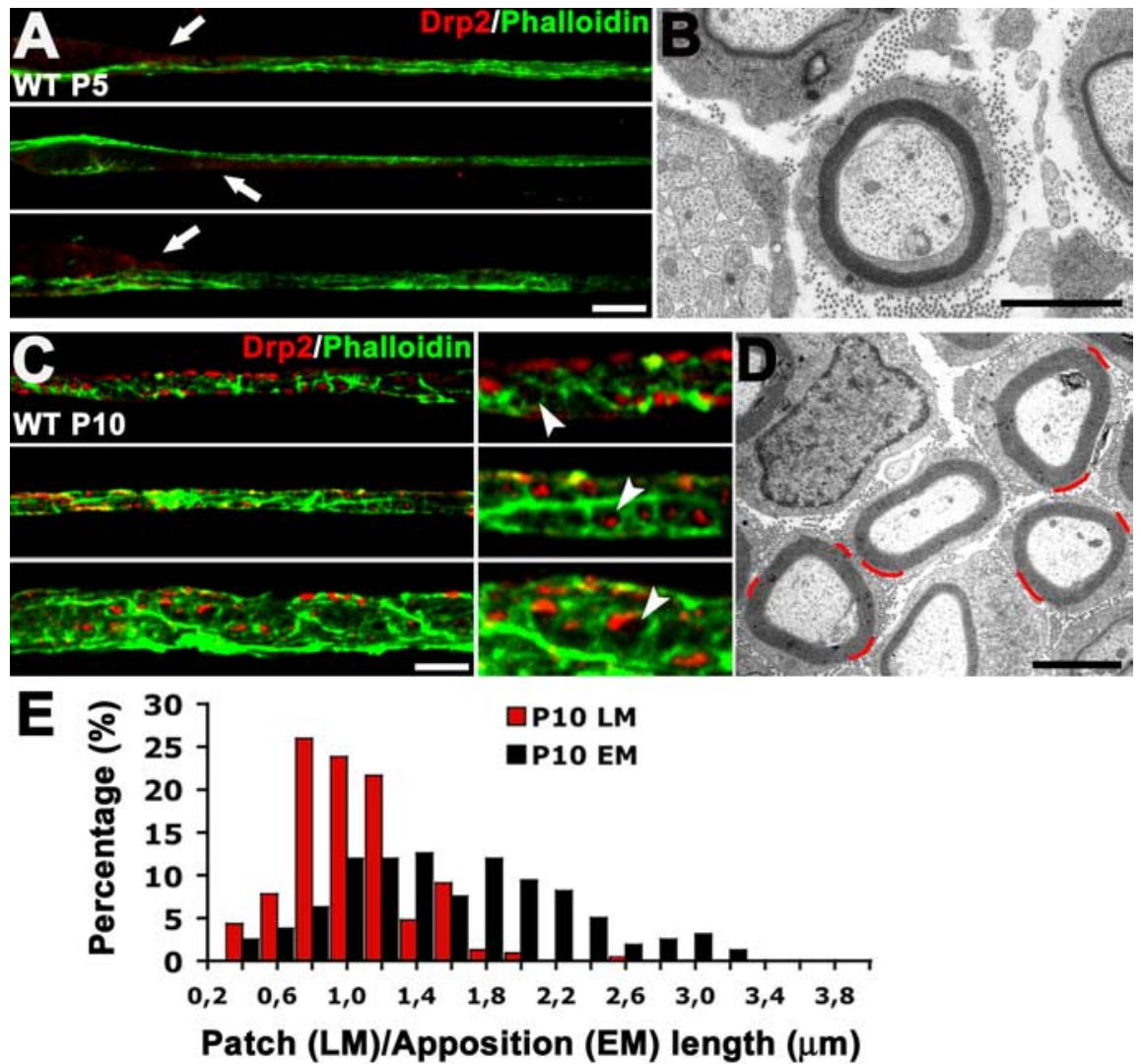

Figure 2. $\quad \boldsymbol{A}-\boldsymbol{E}$, Actin meshwork patterning precedes DRP2 localization. Teased fibers from sciatic nerves of P5 and P10 wildtype mice were immunostained for DRP2 together with FITC-phalloidin to reveal early stages of patch formation. At P5, DRP2 is hardly detectable in perinuclear areas (arrows) $(\boldsymbol{A})$, and at the EM level Schwann cells display an uncompartmentalized cytoplasm $(\boldsymbol{B})$. At P10, the first detectable patterning of the Schwann cell cytoplasm occurs at the level of the actin meshwork ( $\boldsymbol{C}$; green, right panels: higher magnifications of left panel regions), which forms a net-like structure, leaving regular empty spaces that are progressively filled by DRP2 (arrowheads). Small EM appositions are detected at P10 ( $\boldsymbol{D}$, red lines). Scale bars, $\boldsymbol{A}, \boldsymbol{B}$, and $\boldsymbol{D}, 5 \mu \mathrm{m}$; C, $5 \mu \mathrm{m}$ for top and middle panels and $10 \mu \mathrm{m}$ for bottom panels. $\boldsymbol{E}$, Comparison of the length of patches (LM) or apposition (EM) shows that when patches are forming (P10), the distributions do not correspond.

cally, forming a net-like structure around regular empty spaces, some of them filled to different degrees by nascent DRP2-staining (Fig. 2C). Therefore, the patterning of the actin cytoskeleton at P10 already resembles the adult Schwann cell distribution, and precedes the formation of DRP2 ${ }^{+}$patches. Consistent with the small size of $\mathrm{DRP} 2{ }^{+}$patches, appositions by electron microscopy at this age were smaller (Fig. 2D). To further ask whether this initial actin patterning precedes and can drive the formation of appositions, we compared appositions length by electron microscopy with DRP2 patches length at the LM level. As shown in Figure $2 E$, DRP2 patches (LM level) were smaller than appositions (EM level). This unexpected result shows that the initial formation of appositions is independent of DRP2. In contrast, it suggests that a primordial cytoskeletal pattern, here revealed by actin expression, outlines the areas that will subsequently be apposed. Appositions may then stabilize through the appearance/ targeting of the DRP2/periaxin complex.

\section{Cytoskeletal "fences" maintain appositions}

That actin is organized before DRP2 suggests that the cytoskeleton is involved in the formation and maintenance of cytoplasmic compartments. To evaluate this we quantified the distribution of the actin and microtubule networks, and examined the consequence of their pharmacological disruption in vivo.

F-actin is distributed along both longitudinal and transverse cytoplasmic regions, Cajal bands and trabeculae, respectively (Fig. 3). In contrast, the microtubule network is absent from Trabeculae, and is restricted the central domain of Cajal bands, where is flanked by actin (Fig. 3). Cajal bands are $\sim 2 \mu \mathrm{m}$ in width and composed of a prominent $1 \mu \mathrm{m}$ central microtubule network flanked by two $0.5 \mu \mathrm{m}$ actin-rich regions. Actin-rich trabeculae are on average $0.5 \mu \mathrm{m}$ in width (Fig. 3C).

Next, we pharmacologically disrupted the actin or microtubule network in vivo by intraneurial injection of colchicine or cytochalasin-D. After $1 \mathrm{~d}$, animals were killed and single fibers were stained for DRP2, tubulin and phalloidin. To control for potential mechanical damage from the injection we first injected saline solution and showed that compartments were preserved (Fig. 3D). In contrast after Colchicine treatment the microtubule network became undetectable. Consistently a similar treatment performed previously resulted in impairment of myelin basic protein RNA transport to paranodes (Court et al., 2004). Of note, microtubule disruption caused DRP2 ${ }^{+}$patches to change their spatial arrangement (Fig. 3D): patches were no longer longitudinally segregated by the $2 \mu \mathrm{m}$ Cajal bands and domain, which narrowed to widths comparable to those of trabeculae, possibly reflecting the separation provided only by the remaining $0.5 \mu \mathrm{m}$ actin-based "fence" (Fig. $3 E$ ). As expected, decreased Cajal band width resulted in a decrease in the $f$-ratio and a slight increase in the size of DRP2 ${ }^{+}$ patches (Fig. $3 F, G$ ). Thus, the longitudinal Cajal band channel traversing the internode requires an intact microtubule network.

In contrast, f-actin disruption using Cytochalasin-D treatment preserved longitudinal Cajal bands, although their width narrowed to the $1 \mu \mathrm{m}$ microtubule-only network width (microtubule-based "fence") measured in nontreated Schwann cells (Fig. 3D,E). Instead, actin disruption caused the disappearance of trabeculae with fusion of DRP2 ${ }^{+}$patches in the longitudinal orientation (Fig. $3 D$ ). As a result the $f$-ratio decreased, and patch sizes increased considerably apparently because of patch fusion (Fig. 3D, $G$ ). Thus, the transverse trabeculae require an intact actin cytoskeleton.

Together, these results indicate that $\mathrm{DRP}_{2}{ }^{+}$patches in Schwann cells are highly dynamic structures whose distribution and size is maintained by cytoskeletal elements acting as "fences." In the absence of cytoskeletal fences, DRP2 ${ }^{+}$patches invade the available cytoplasmic space.

\section{Utrophin is required for proper}

\section{cytoplasm compartmentalization}

Our data so far indicate that the actin cytoskeleton is required to maintain compartments. In addition, Cajal bands and appositions appear before $\mathrm{DRP} 2{ }^{+}$patches, suggesting that molecules that reside in Cajal bands and bind actin may have a role in this process. Because periaxin is part of the DGC and its absence 

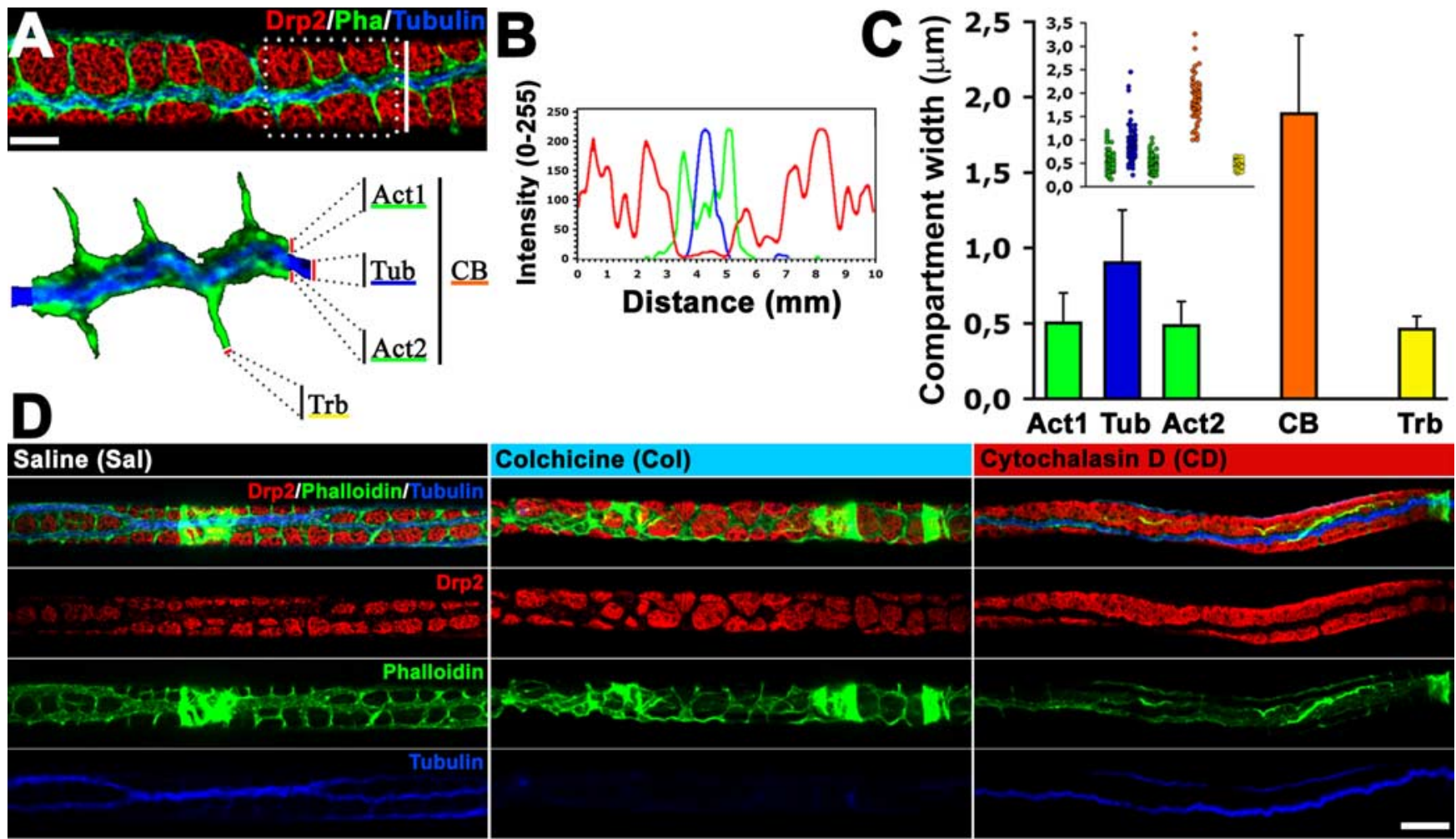

Threshold Drp2
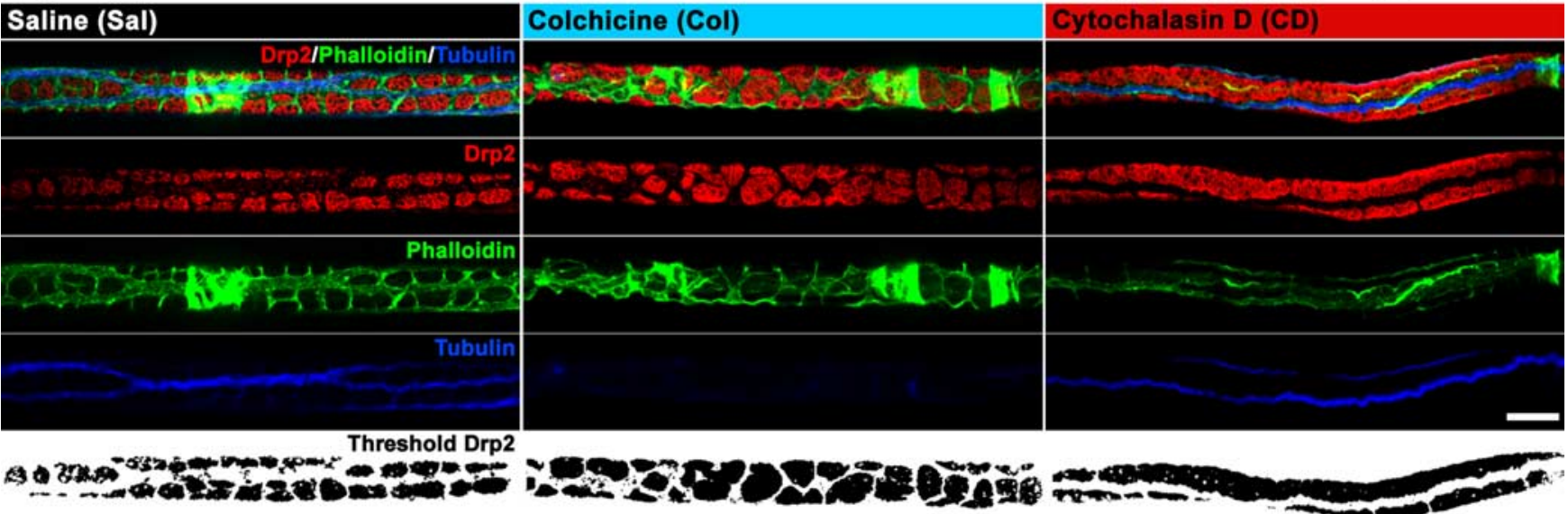

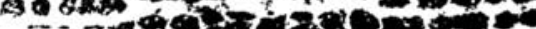
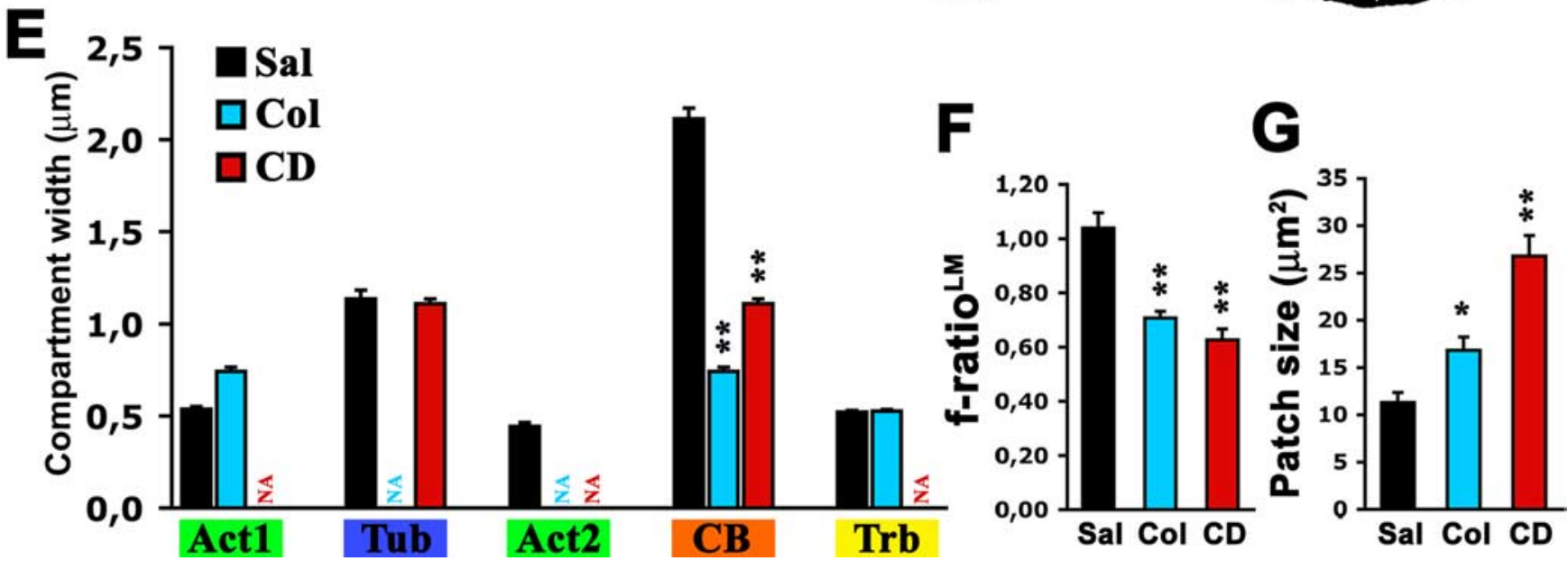

Figure 3. Cytoskeletal component distribution in Schwann cells and their role as molecular fences. $A-C$, Analysis of cytoplasmic subcompartments defined by their cytoskeletal constituents. $A$, Staining for DRP2, actin (using FITC-phalloidin), and tubulin reveals different domains within the Schwann cell cytoplasm. Cajal bands (CB) have a central, tubulin-rich domain (Tub), flanked by actin-rich regions (Act1 and Act2); in trabeculae (Trb, transversal to (B) only actin is detected. Scale bar, $5 \mu \mathrm{m}$. $\boldsymbol{B}$, Intensity profile of the three stainings (color coded as in $\boldsymbol{A}$ ) across the continuous line drawn on $\boldsymbol{A}$. C, Mean thickness of each domain; the inset shows the individual values from which the bar graph was generated. $\boldsymbol{D}-\boldsymbol{F}$, Disruption of microtubules or actin filaments in vivo results in redistribution of DRP2 ${ }^{+}$patches. Sciatic nerves of WT mice were injected with colchicine or cytochalasin-D to disrupt the microtubule and actin networks, respectively. Nerves were processed for immunohistochemistry $1 \mathrm{~d}$ after injection. $\boldsymbol{D}$, Either drug completely disrupts the respective cytoskeletal network, as revealed by immunostaining. Saline injection does not alter cytoplasmic or patch organization (right). After microtubule disruption (middle), Cajal bands are no longer recognized and patches lose their longitudinal orientation, but they remain separated by the actin network. After actin filament disruption (right), patches fuse together in the longitudinal axis, but the intact microtubule network maintains thinner Cajal bands. Scale bar, $10 \mu \mathrm{m}$. In $\boldsymbol{E}$, the subcompartments defined above were quantified after each treatment. $\boldsymbol{F}$, The $f$-ratio of cytoskeletal-disrupted nerve fibers decreased compared with the control value, which indicates a decrease in the $C$ ajal band area relative to patch area. Conversely, the size of patches increases after microtubule disruption and more dramatically after actin filament disruption (G). (NA refers to domains no longer present; ${ }^{*} p<$ $0.005,{ }^{* *} p<0.000$, Student's $t$ test; $n=3$ for each condition.)

impairs compartments (Sherman et al., 2001; Court et al., 2004), we reasoned that the DGC component utrophin, which resides specifically in Cajal bands (Albrecht et al., 2008) and is the only dystrophin in Schwann cells that contains an actin-binding domain, should be crucially important. Thus, we asked whether Schwann cells lacking utrophin in vivo formed normal compart- ments by measuring the $f$-ratio in 4-week-old utrophin-null sciatic nerves. Utrophin-null Schwann cells display smaller DRP2 ${ }^{+}$ patches (Fig. 4A) and this decrease was reflected in increased $f$-ratio (Fig. $4 B$ ). Interestingly the $f$-ratio increase was positively related to fiber diameter (Fig. 4C). Given the correspondence between $\mathrm{DRP} 2^{+}$patches in light microscopy and appositions in 


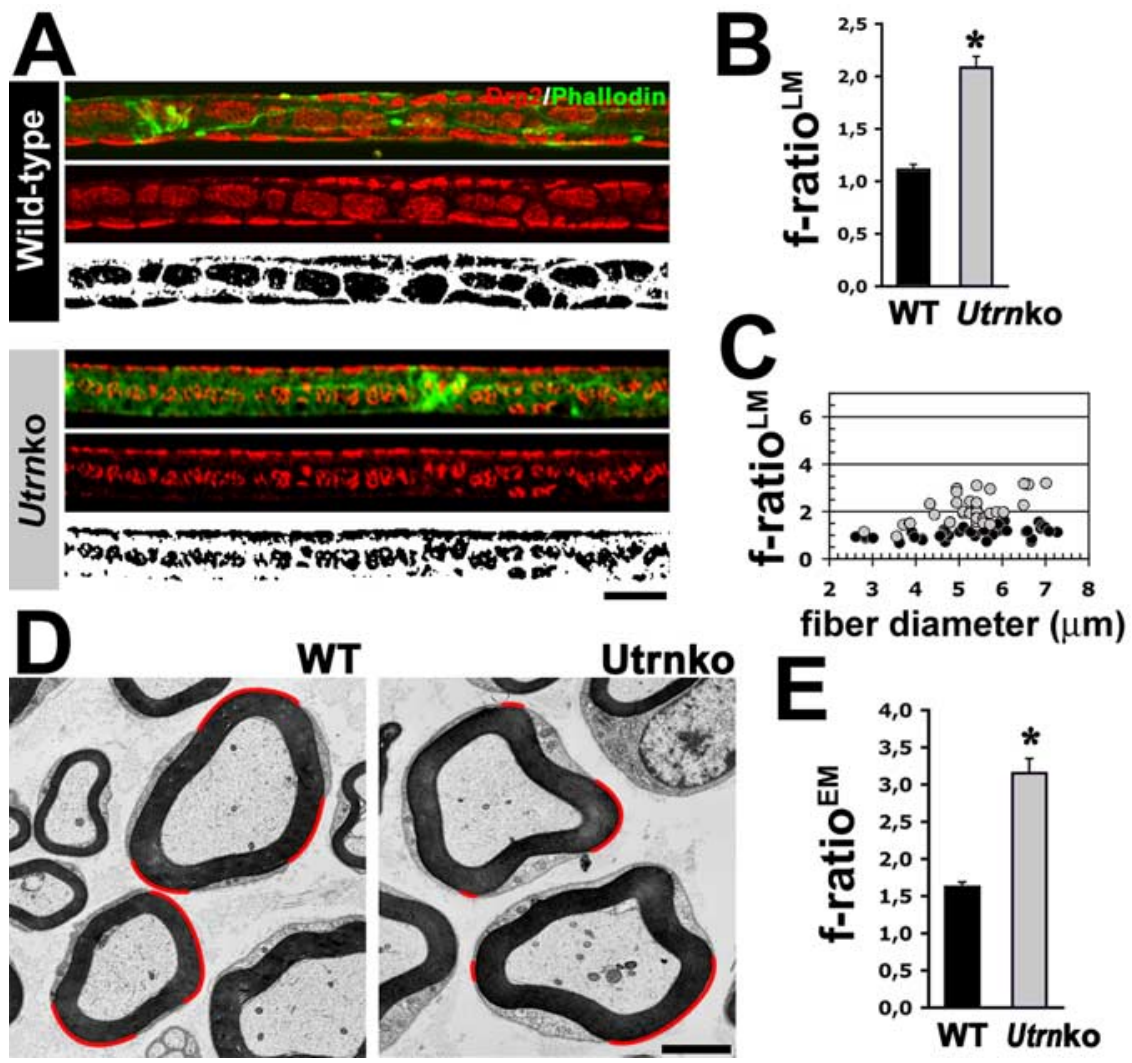

Figure 4. The actin binding protein utrophin is required for Schwann cell cytoplasmic compartmentalization. $\boldsymbol{A}$, Teased fibers from 4-week-old WT and utrophin null mice were stained for DRP2 (red) and counterstained with FITC-phalloidin (green). Utrophin null (Utrnko) Schwann cells show smaller DRP2 ${ }^{+}$patches than WT Schwann cells. $\boldsymbol{B}$, The mean $f$-ratio at the LM level is higher in utrophin null than WT. C, Graph showing $f$-ratio values in relation to fiber diameters; a positive correlation between fiber diameter and $f$-ratio is observed in utrophin mutants. $\boldsymbol{D}$, As expected, utrophin null Schwann cells present smaller EM appositions (red lines) than WT Schwann cells. $E$, At the EM level, the $f$-ratio is also increased in utrophin null mice. ( $n=3$ for each mutant/WT pair; ${ }^{*} p<0.0001$; error bars indicate SEM.) Scale bars: $\boldsymbol{A}, 10 \mu \mathrm{m} ; \boldsymbol{D}, 2 \mu \mathrm{m}$.

electron microscopy (Fig. $1 C$ ), we also calculated an $f$-ratio at the EM level by measuring the ratio between the length ( $\operatorname{arc})$ of the plasma membrane above cytoplasmic regions and the plasma membrane above appositions (Fig. 1C, EM). In WT nerves, $f$-ratio values at the EM level ( $f$-ratio ${ }^{\mathrm{EM}}$, Fig. $\left.4 E\right)$, were higher than those calculated at the LM level, probably because of differences in the technique (see methods for an in depth comparison between $f$-ratio analysis at the EM and LM levels). However the relevant characteristics of the $f$-ratio, the conservation between 4 and 10-week-old WT nerve fibers (see Fig. 6B) and between fibers of different diameters (WT in supplemental Fig. 2, available at www.jneurosci.org as supplemental material) were maintained between the LM and EM analysis. As expected, utrophin-null myelinated fibers showed reduced appositions by electron microscopy (Fig. $4 D$ ), with a consequent increase in the EM $f$-ratio (Fig. 4E).

Role of laminin-DG association in compartmentalization Compartmentalization of the Schwann cell cytoplasm requires periaxin (Court et al., 2004) and utrophin (Fig. 4), which associates with the DGC in Schwann cells (Imamura et al., 2000). DG in turn interacts with laminins in the Schwann cell basal lamina (Yamada et al., 1994, 1996). To test whether Schwann cell compartmentalization depends on DG and its and extracellular (laminins) linkage, we isolated nerve fibers from mice lacking DG specifically in Schwann cells (thereafter referred as P0CreDGko or DG null), or defective in the main Schwann cell laminins, laminin-2 (211) or -8 (411). The $f$-ratio was calculated by light microscopy and electron microscopy as described.

In Schwann cells with $D G$ deletion $\mathrm{DRP}_{2}{ }^{+}$patches were still present (Fig. $5 A$ ), but they were smaller and disorganized compared with aged-matched WT nerve fibers. As a consequence Cajal band size increased, and the $f$-ratio was significantly higher (Fig. 5B). By comparing the cross-sectional length distribution of $\mathrm{DRP} 2{ }^{+}$patches and ultrastructural apposition at the EM level, we confirmed that changes in $\mathrm{DRP}^{+}$in DG null Schwann cells reflected a morphological change in appositions and not a decrease in the expression levels of DRP2 (Fig. $6 A, B$ ).

To ask whether molecules in the basal lamina were contributing to the formation of compartments we analyzed nerves from dystrophic $\left(D y^{2 j / 2 j}\right)$ mice, which carry a mutation in the laminin- $\alpha 2$ gene resulting in defective laminin-2/211 polymerization (Xu et al., 1994). Nerve fibers from 4-week-old $D y^{2 j / 2 j}$ mice exhibited smaller DRP2 ${ }^{+}$patches (Fig. 5A) and a corresponding increase in Cajal bands and in the $f$-ratio when compared with agematched WT fibers (Fig. 5B). However the disruption of patches and the increase in $f$-ratio in $D y^{2 j / 2 j}$ Schwann cells were not as dramatic as in DG null cells. As before, ultrastructural analysis confirmed a morphological disruption of apposition with increases in Cajal band areas in $D y^{2 j / 2 j}$ nerves (Fig. $6 A, B$ ). The $f$-ratio calculated at the EM level increased in sciatic nerves from P0CreDGko and $D y^{2 j / 2 j}$ mice (Fig. $6 \mathrm{~B})$, to similar extent to the increase found using the $f$-ratio at the LM level.

Laminin 8-411 $(\alpha 4 \beta 1 \gamma 1)$ is also present in the Schwann cell basal lamina. To ask whether laminin-8 is required for compartments, we studied nerves from laminin- $\alpha 4$ null (Lama4ko) mice (Thyboll et al., 2002) and found that laminin-8 null Schwann cells have DRP2 ${ }^{+}$patches and $f$-ratio values comparable to WT animals (Fig. 5A, B). Thus, laminin-2, but not laminin-8, is important for compartmentalization of the Schwann cell outer cytoplasm. In addition, because both $D y^{2 j / 2 j}$ and Lama4-null mice have a similar dysmyelinating phenotype in distal nerves (Wallquist et al., 2005); this suggests that the abnormal compartments found in $D y^{2 j / 2 j}$ were not due to a developmental delay in radial sorting and subsequent myelination.

These results demonstrate that both DG and laminin-2 are required for maintenance of DRP2 ${ }^{+}$patches and their structural correlate (appositions), indicating that DG is a receptor for laminin-2 in this function. To genetically test whether the interaction between DG and laminin is required for formation of appositions, we analyzed nerves from the myd/myd (Large ${ }^{\text {myd }}$ ) mice. These mice are a model of Congenital Muscular Dystrophy $1 \mathrm{D}$, and harbor a mutation in the Large glycosyltransferase protein that results in the hypoglycosylation of its substrate $\alpha-D G$, decreasing $\alpha$-DG binding to basal lamina ligands, including 
laminin-2 (Grewal et al., 2001; Michele et al., 2002). DRP2 ${ }^{+}$patches in 4-week-old myd/myd nerves were smaller than WT patches (Fig. 5A) and showed a significant increase in $m y d / m y d$-ratio compared with WT (Fig. 5B).

In normal nerves, even though the $f$-ratio remains constant for varying fiber diameter, we noticed that the size of patches was positively related to nerve fiber diameter (data not shown). Because the defects in compartmentalization in DG-null, $D y^{2 j / 2 j}$ and $m y d / m y d$ Schwann cells were always associated with smaller $\mathrm{DRP}^{+}{ }^{+}$patches, we asked whether the $f$-ratio in these mutants varied with nerve fiber diameter. We therefore plotted the individual $f$-ratio values of different diameter nerve fibers from 4 and 10-week-old mice. In WT nerve fibers, the $f$-ratio remains constant across fiber diameters as already described (Figs. $1 B, 4 C, 5 C$ ). In contrast, in utrophin null, $D y^{2 j / 2 j}$, and myd/myd Schwann cells, small fibers showed better-preserved $f$-ratio values than big- diameter fibers (Figs. 4C, 5C). This was also confirmed at the EM level for DG-null and $D y^{2 j / 2 j}$ Schwann cells (supplemental Fig. 2, available at www. jneurosci.org as supplemental material). Thus, in the absence of DG-laminin interactions, Schwann cells are only able to form small DRP2 ${ }^{+}$patches, sufficient to produce normal compartmentalization of the Schwann cell cytoplasm in small, but not large fibers. These data collectively show that laminin-2, its polymerization, DG, and its glycosylation are all required for proper cytoplasmic compartmentalization in myelinating Schwann cells.

\section{Laminin-2 and DG have delayed} formation of compartments

Our results suggest that compartments form via actin patterning, which could be dependent or independent of the DGC complex. To ask whether laminin-2/DG were responsible for creation of compartments, in addition to their maintenance, we studied DG deficient and Dy $2 j^{2 j}$ Schwann cells at P10, during initial formation of appositions. Because DRP2 staining is not a good reflection of EM appositions during the first stages of cytoplasmic compartmentalization (Fig. $2 \mathrm{E}$ ) we assessed the distribution of apposition length by electron microscopy. At P10, $f$-ratio values were not significantly different between WT, DG null, $D y^{2 j / 2 j}$ Schwann cells (Fig. $6 C$ ), although the distribution of apposition length was slightly shifted toward smaller values in the mutants, especially DG-null (Fig. 6D). However, the number of apposition per fiber was lower in mutant nerves, because both DG null and $D y^{2 j / 2 j}$ Schwann cells showed an increase percentage of fibers with no or 1-2 appositions when compared with WT Schwann cells (Fig. 6E). Because fibers without appositions cannot be included in the $f$-ratio analysis, our results imply that in the mutants analyzed there is a delay in the formation of cytoplasmic compartments. Once compartmentaliza- tion takes place is undistinguishable from WT compartmentalization, at least at early time points (P10).

\section{Schwann cell cytoplasmic compartmentalization and elongation capacity}

During postnatal development, promyelinating Schwann cells that have sorted individual axons start to myelinate them. At the same time they elongate longitudinally, increasing their size several-fold (Court et al., 2004). Schwann cells lacking periaxin display a nearly complete absence of appositions and a reduction in their longitudinal growth, this lead to propose a relationship between Schwann cell compartmentalization and elongation (Court et al., 2004). However, absence of periaxin could affect Schwann cell elongation in several ways, and other examples in which both compartments and IL are reduced are needed to strengthen the association between compartmentalization and elongation capacity. Interestingly, it is already known that absence of laminin-2 causes a neuropathy with short IL (Jaros and Jenkison, 1983; Di Muzio et al., 2003), but the 


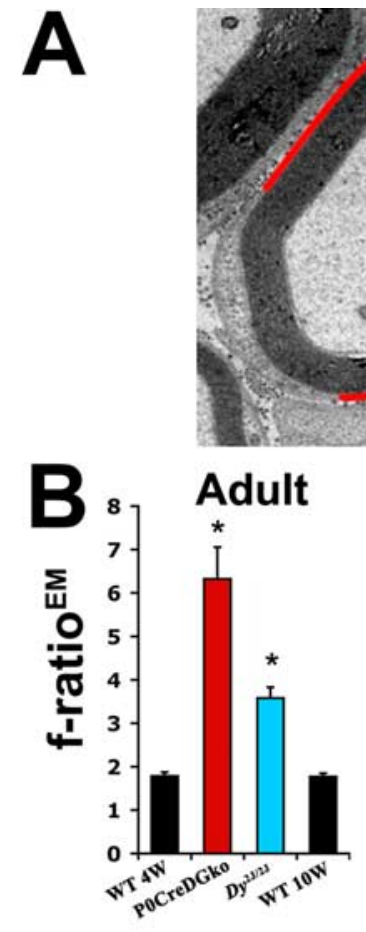

C
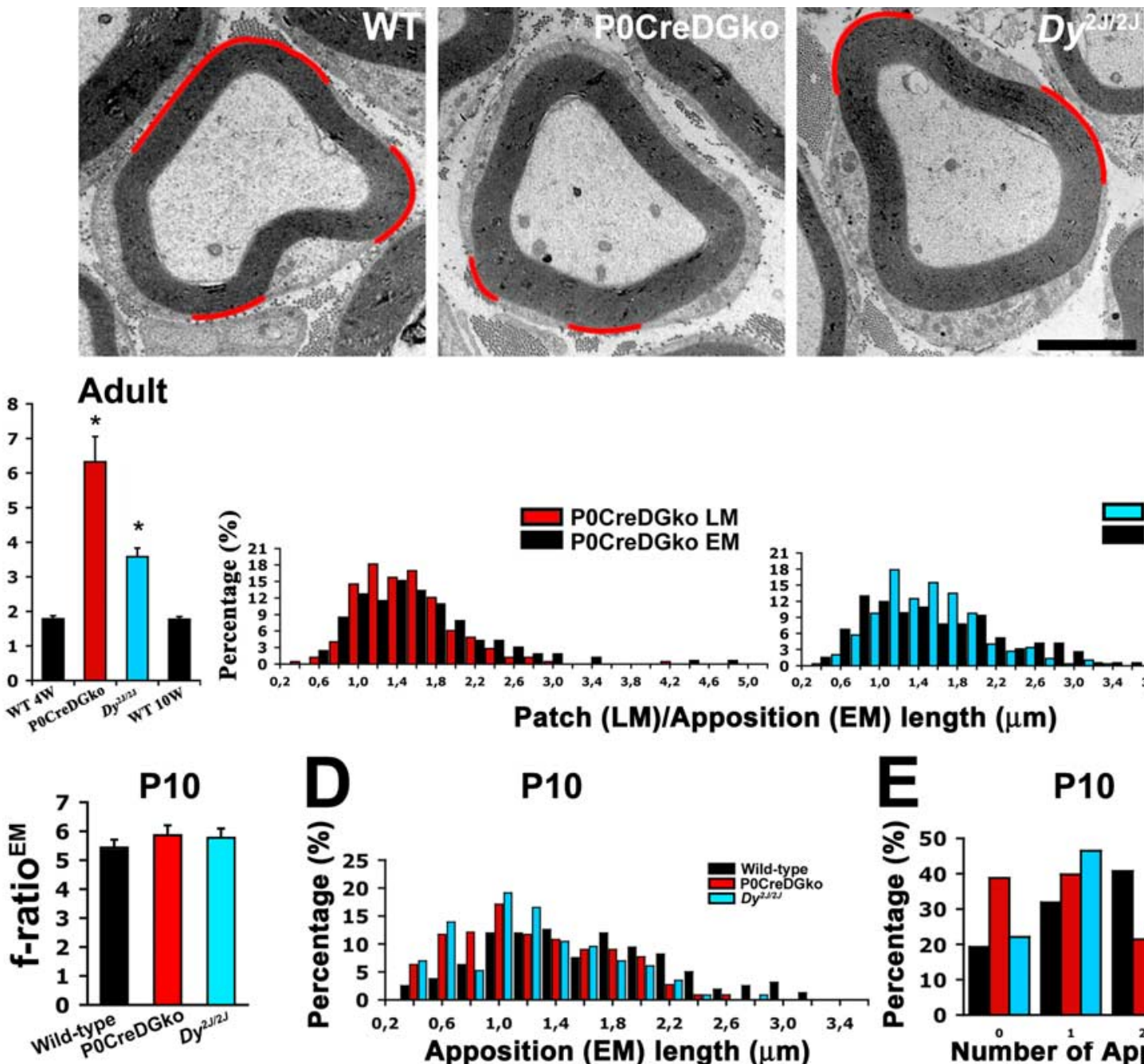

Patch (LM)/Apposition (EM) length ( $\mu \mathrm{m})$
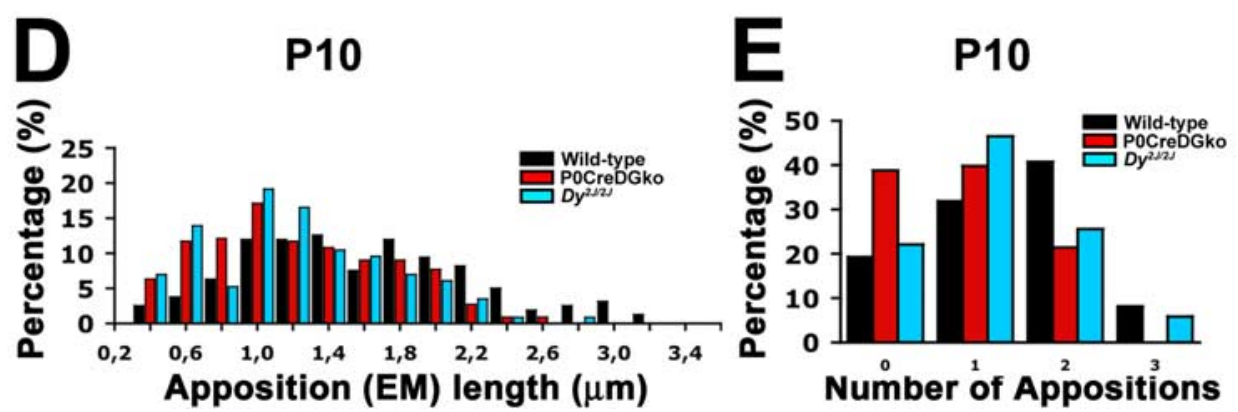

Figure 6. Compartmentalization analysis at the EM level of mutant nerve fibers and during WT (normal) apposition formation. $A$, At the EM level both POCreDGko and Dy $2 j / 2 j$ Schwann cells present smaller appositions (red lines) compared with WT fibers. $\boldsymbol{B}$, The $f$-ratio ${ }^{\mathrm{EM}}$ is increased in Schwann cells from POCreDGko and $D y^{2 \mathrm{j} / 2 j}$ mice with a magnitude similar to the analysis performed at the $L M$ level (compare with Fig. 5B). LM patches and EM apposition lengths show similar distributions for P0CreDGko and Dy ${ }^{2 j / 2 j}$ Schwann cells. $C$, Similar $f$-ratio ${ }^{\text {EM }}$ values at P10 between WT, P0CreDGko, and $D y^{2 j / 2 j}$ Schwann cells. D, The distribution of apposition lengths are similar between mutants and WT nerves. $\boldsymbol{E}$, Mutant mice have fewer appositions at P10.

reason for this is unknown. The abnormal cytoplasmic compartmentalization detected in DG null, $D y^{2 j / 2 j}$, and myd/myd Schwann cells offers a unique opportunity to investigate whether partial cytoplasmic domain disruption impairs the Schwann cell elongation capacity. To this end, we measured Schwann cell IL from mutant mice. At P5, the time when many Schwann cells start to myelinate, but no DRP2 ${ }^{+}$patches are present, ILs were comparable between DG null, $D y^{2 j / 2 j}$ and WT Schwann cells (Fig. 7A), demonstrating that initial Schwann cell size is independent of DG/laminin-2 interaction, and consistent with our observations that at P5, the cytoplasm of Schwann cells is still not compartmentalized (Fig. 2A,B). At P10, when small DRP ${ }^{+}$patches begin to appear (Fig. $2 C, D$ ) DG null and $D y^{2 j / 2 j}$ fibers begin to show reduced IL (Fig. 7A). At 4 weeks, a time when WT Schwann cells reach their mature cytoplasm compartmentalization, utrophin-null, DG-null, $D y^{2 j / 2 j}$, and $m y d / m y d$ Schwann cells display a reduction in ILs (Fig. 7A). Importantly in Lama4ko Schwann cells, which show normal cytoplasmic compartmentalization, internodal lengths were comparable to WT values (Fig. 7A), ruling out any contribution of the early dysmyelinating phenotype, or unrelated laminin effects. This strongly supports an association between compartments and regulation of IL. To further strengthen this relation, we studied the correlation between IL and fiber diameter. We had already noted that in the mutant mice, particularly $D y^{2 j / 2 j}$ and $m y d / m y d$, small fibers were less affected (Fig. $5 C$ ). Consistently, ILs of small-diameter $D y^{2 j / 2 j}$ and $m y d / m y d$ fibers also display normal (WT) values at both 4 and 10 weeks (Fig. 7B).

\section{Cytoplasmic compartmentalization and microtubule} network organization

Schwann cell elongation and myelin synthesis requires transport and targeting of molecules to distant Schwann cell regions (for review, see Trapp et al., 2004)). In periaxin-null mice, the Schwann cell microtubule network becomes progressively disorganized at distal regions, near nodes of Ranvier (Court et al., 2004). Because microtubule-based transport is required for transport and targeting of cargoes to distal Schwann cell domains (Kidd et al., 1994) it is possible that defective cytoplasmic compartmentalization reduces IL by impairing cytoskeleton-based transport. As described above, immunofluorescence analysis showed that microtubules in WT Schwann cells are mainly located in Cajal bands, and forms a tight network running from the perinuclear region to the most distal Schwann cell domains near nodes of Ranvier (Fig. 7C) (Kidd et al., 1994). In contrast, both DG null and $D y^{2 j / 2 j}$ Schwann cells displays disorganized microtubule 

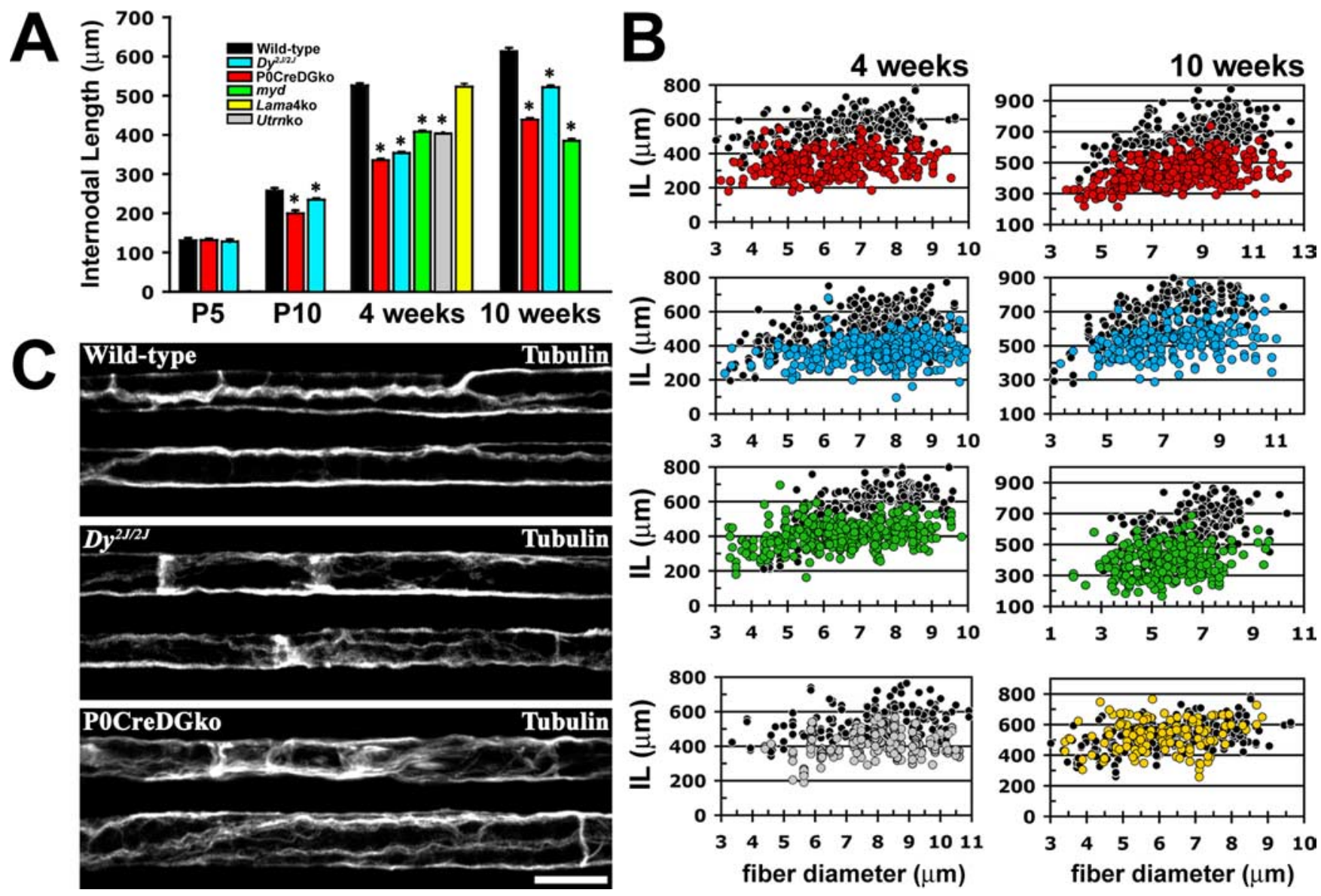

Figure 7. Disruption of patches correlates with impairment in Schwann cell elongation. Schwann cell ILs were measured from wild-type, POCreDGko, Dy ${ }^{2 j / 2 j}$, myd, utrophin null (Utrnko) and Lama4ko mice. $\boldsymbol{A}$, Mean internodal length for each genotype from 5- or 10-d-old and 4- or 10-week-old mice. $\boldsymbol{B}$, Internodal lengths in relation to fiber diameter at 4 and 10 weeks of age (color coded as in $\boldsymbol{A}$ ). Internodal distances in POCreDGko, Dy ${ }^{2 j / 2 j}$, utrophin null, and myd decrease to a larger degree in big-diameter Schwann cells, with small-diameter ones showing IL values comparable to wild-type Schwann cells; this observation is in agreement with the fiber diameter dependence of the $f$-ratio in transgenic animals. Internodal distances in the Lama4ko Schwann cells, which have normal $f$-ratio values, are comparable to those of wild-type animals ( $n=3$ for each mutant/WT pair; ${ }^{*} p<0.0001$, error bars indicate SEM). $C$, Teased fibers from 4 -week-0ld wild-type, $D y^{2 j / 2 j}$, and POCreDGko mice immunostained with an antibody against tubulin. In wild-type Schwann cells, the microtubule network is restricted to Cajal bands and presents a compact pattern of staining. In contrast, microtubule tracks become disorganized when the cytoplasmic space increases in the mutants (arrows). Scale bar, $10 \mu \mathrm{m}$.

network (Fig. 7C), which are not longer restricted to the central region of Cajal bands but are spread in the cytoplasmic spaces.

Defects in compartments in sural nerve from an MDC1A neuropatic patient

In humans, laminin-2 mutations (merosin-deficient congenital muscular dystrophy, MDC1A) can lead to muscular dystrophy and a neuropathy characterized by short IL and reduced nerve conduction velocity (Shorer et al., 1995; Mora et al., 1996; Belpaire-Dethiou et al., 1999; Deodato et al., 2002; Di Muzio et al., 2003). To determine whether Schwann cells in human MDC1A exhibit a defect in cytoplasmic compartmentalization that could explain the reduced IL, we measure the $f$-ratio ${ }^{\mathrm{EM}}$ from the sural biopsy of an MDC1A patient, from which a neuropathy with reduced IL was directly documented (Di Muzio et al., 2003) and a biopsy from a control patient with a chronic inflammatory demyelinating neuropathy, but morphologically normal sural nerve biopsy.

To first verify whether the degree of compartmentalization was conserved between different species (human and mouse) and between different nerves (sciatic and sural nerves), we compared the $f$-ratio ${ }^{\mathrm{EM}}$ of the human sural nerve control to the $f$-ratio ${ }^{\mathrm{EM}}$ of 10 -week-old mouse sciatic nerve and found that they were similar
(Fig. 8A). Thus, the ratio between cytoplasmic and apposition compartments is conserved across species. Fibers in the sural nerve derived from the MDC1A patient showed an increase in $f$-ratio ${ }^{\mathrm{EM}}$ value compared with the control patient and appositions in MDC1A Schwann cells were consistently smaller than in the control (Fig. 8). Thus, laminin-2 deficiency in human MDC1A causes a defect in cytoplasmic compartment formation similar to that observed in the $D y^{2 j / 2 j}$ mice. Together with our data showing a correlation between Schwann cell compartmentalization and elongation capacity in different mutant animals, these data suggest that compartmentalization defects may be at the basis of the reduced IL observed in this patient (Di Muzio et al., 2003). These results also confirm that the $f$-ratio ${ }^{\mathrm{EM}}$ analysis share the most relevant characteristics with the $f$-ratio analysis at the LM level, and can be used to detect Schwann cell cytoplasmic compartmentalization defects in human neuropathies.

\section{Discussion}

We show that laminin-2 and the DGC are required for compartmentalization of the Schwann cell cytoplasm and achievement of correct IL. In myelinated nerves an optimal relationship exists between axon diameter, myelin thickness, and IL to achieve maximum conduction velocity. We show that after myelination, the 


\section{A Hu MDC1A}

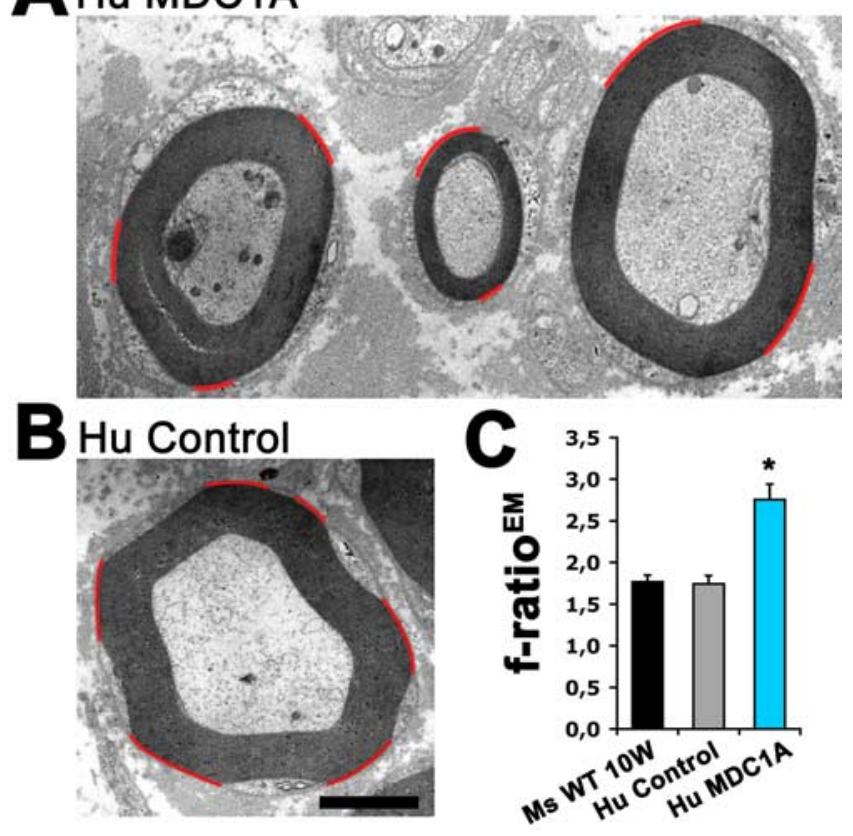

Figure 8. A-C, Laminin-2 mutations in human lead to defects in Schwann cell compartmentalization. EM sections from sural nerves derived from a muscular dystrophy (MDC1A) and a control patient were analyzed for Schwann cell cytoplasmic compartmentalization. MDC1A Schwann cells present smaller appositions (red lines) $(\boldsymbol{A})$ when compared with appositions present in control patient $(\boldsymbol{B})$. $\boldsymbol{C}$, When compared by the quantitative $f$-ratio ${ }^{\mathrm{EM}}$ analysis, $\mathrm{MDC} 1 \mathrm{~A}$ Schwann cells present higher values than control cells. Notice that control human $f$-ratio ${ }^{\mathrm{EM}}$ values are comparable to values of adult mice (10 weeks old). Scale bar, $5 \mu \mathrm{m}$.

actin cytoskeleton polarizes into cytoplasmic domains that are later occupied by DRP2-periaxin. In adult Schwann cells the actin and microtubule network form fences that maintain compartments by restricting the location of DRP2 positive patches.

Single genetic disruption of laminin-2, DG, DG glycosylation and utrophin leads to changes in the proportion of cytoplasmic domains and reduce elongation capacity of Schwann cells, suggesting a common pathogenesis for the human neuropathies due to mutations in these components of the DGC. These data support the idea proposed by Brophy and coauthors that proper balance between cytoplasmic domains in myelin-forming Schwann cells allows achievement of proper IL (Court et al., 2004).

\section{Compartmentalization of the Schwann cell cytoplasm}

Schwann cells are polarized into domains involved in diverse functions. Although a great effort has been dedicated to study nodal-paranodal domains (for review, see Poliak and Peles, 2003), little is known about compartmentalization along the internode. The function of Cajal bands remained unknown until it was discovered that its derangement in mice lacking periaxin decreased longitudinal elongation of Schwann cells (Court et al., 2004). Recent studies showed that patches and Cajal bands harbor different DGC complexes and are able to compartmentalize proteins into these specific domains (Albrecht et al., 2008).

To investigate the molecular mechanisms involved in domain formation, we first developed a method to quantitatively assess the compartmentalization degree of Schwann cell cytoplasm ( $f$ ratio). This dimensionless quantity is conserved across fiber diameters, ages and species, suggesting that a precise proportion between cytoplasm rich and free regions is required for the proper function of Schwann cells. Similar properties characterize the g-ratio (fiber diameter/axon diameter), another dimensionless quantity conserved across fiber diameters and ages that is widely used in neuropathology.

\section{Actin cytoskeleton in the formation of cytoplasmic compartments}

Periaxin, which associate with the DGC via DRP2, is required for cytoplasmic compartmentalization(Court et al., 2004). Critical questions are whether periaxin and the DGC are involved in the formation or only the stabilization of cytoplasmic compartments, and which is the main organizer of compartmentalization in Schwann cells. Here we show that the first stages of cytoplasm segregation into discrete domains are independent of DRP2, but are characterized by patterning of the actin cytoskeleton that create actin-free regions, subsequently filled with DRP2. The mechanism by which actin becomes segregated in restricted domains is presently unknown, a possibility is that actin contraction by myosin II and cross-linking by cross-linker proteins leads to the early patterning observed in Schwann cells (Reichl et al., 2008; Wang et al., 2008). After this prepatterning takes place, the DGC may stabilize this cytoplasmic configuration through its linkage with utrophin first and DRP2/periaxin later. Consistent with this hypothesis, lack of utrophin affects apposition, even though utrophin itself is localized only in Cajal bands (Albrecht et al., 2008). Possibly DRP2 or DP116 cannot compensate for lack of utrophin, because they do not contain an actin-binding domain.

\section{Maintenance of SC compartments}

In mature Schwann cells, both the actin and microtubule cytoskeleton segregate to defined domains of the cytoplasm. Depolymerization of the cytoskeleton in vivo resulted in fusion of patches with an increase in their size. This suggests that the cytoskeleton provide fences that restrict the lateral movement of DRP2 patches. Because acute cytoskeleton disruption determines the rapid reorganization of patches, compartments may be dynamic structures in constant remodeling.

\section{Role of laminin-DG association in Schwann cell compartmentalization}

We show that patches, or their ultrastructural correlate appositions, are dependent on DG, laminin-2 polymerization, and the association of laminin-2 to $\alpha$-DG. When any of these factors are disrupted, patches become smaller and disorganized to various degrees. Our data suggest, but do not prove conclusively, that both formation and maintenance of patches are impaired in DGC mutants. A similar matrix/receptor/cytoskeleton network has been documented in muscle fibers in vitro, and is disrupted when laminin is unable to polymerize (Yurchenco et al., 2004). It is likely that other cell types use the DGC in similar ways to organize domains and barriers that underlies complex structures.

Reduction of Schwann cell patches alters the balance between appositions and Cajal bands, resulting in higher $f$-ratio values. The degree of disruption is not equal and depends on the targeted component of the basal lamina/receptor system. Higher $f$-ratio values are detected in DG-null Schwann cells, but because DRP2 patches can still form another protein may compensate for this function, by associating with DRP2, periaxin, or directly with the actin cytoskeleton. Among other laminin receptors integrin $\alpha 6 \beta 4$ does not fulfill this role because DRP2 patches can form even in the absence of both DG and $\alpha 6 \beta 4$ integrin (Nodari et al., 2008). However in this situation a $\alpha 7 \beta 1$ is upregulated and $\beta 1$ integrin relocalizes to appositions, suggesting that $\alpha 7 \beta 1$ integrin 
may be the receptor compensating for the absence of DG (Nodari et al., 2008). Laminin polymerization defects in $D y^{2 j / 2 j}$ mice and glycosylation defects of DG in myd mice results in a lower increase of the $f$-ratio, probably reflecting the partial defects in laminin and DG function is these mutants (Colognato et al., 1999; Previtali et al., 2003; Yang et al., 2005).

Our results define the molecular participants of cytoplasmic compartmentalization in addition to periaxin. They suggest that it is not appositions per se but rather the balance between appositions/Cajal bands that is required to maintain proper organization of the internode.

\section{Elongation of Schwann cells is impaired when compartmentalization and the microtubule network are imperfect}

Complete absence of appositions in periaxin-null mice reduces Schwann cell internodal distances by half at 3 weeks of age (Court et al., 2004). Here we show that targeting the function of the DGC produce intermediate levels of patches disruption and reduced internodal distances, supporting that the elongation capacity of Schwann cells depends on its degree of cytoplasmic compartmentalization. However a strict correlation between the different degrees of patches disruption and the mean IL values from DG null, $D y^{2 j / 2 j}$ and myd/myd mice was not observed ( $f$-ratio values: DG null $>$ myd/myd $>D y^{2 j / 2 j}$ and IL: DG null $<D y^{2 j / 2 j}<$ myd/ myd). This suggests that other factors not detected by $f$-ratio analysis are also important in regulating IL.

One important question is how cytoplasmic compartmentalization may lead to reduced Schwann cell growth capacity; in periaxin-null Schwann cells, which show complete absence of appositions, a disorganized microtubule network was detected and targeting of MBP (myelin basic protein) mRNA to distal Schwann cell domains was impaired (Court et al., 2004). Our results shown that also in DG null and $D y^{2 j / 2 j}$ Schwann cells the microtubule network is disorganized, possibly impairing targeting proteins, mRNA and other cargoes to distal regions.

\section{A common pathogenetic mechanism underlines the reduced IL in different human neuropathies}

Charcot-Marie-Tooth 4F, MDC1A, and MDC1D are neuromuscular diseases due to loss-of-function mutations in PERIAXIN, $\alpha 2$ LAMININ and LARGE, respectively. In the first two diseases a peripheral neuropathy has been described (pure, earlyonset and severe dysmyelinating and demyelinating neuropathy in Charcot-Marie-Tooth 4F and a mild dysmyelinating neuropathy in MDC1A) whereas mutations in Large are known to cause a neuropathy in mice. These neuropathies all include dysmyelination with short internodes (Jaros and Jenkison, 1983; Di Muzio et al., 2003; Court et al., 2004). The DGC is thus central to the pathogenesis of these neuropathies, because interference with its extracellular or intracellular linkage (laminin-2 and DRP2/periaxin, respectively) is associated with a similar phenotype of shorter internodes. Because DG mutants phenocopy laminin-2, but not laminin-8, mutants, $\alpha$-DG is probably a specific receptor for laminin-2 in Schwann cells for this function. It remains to be determined why periaxin mutations also result in a severe demyelination that is not seen in the absence of $D G$, Large or laminin-2. Because a severe neuropathy is seen in a Charcot-Marie-Tooth $4 \mathrm{~F}$ patient expressing a truncated periaxin, that includes the DRP2 binding region in the $\mathrm{N}$-terminal domain (Takashima et al., 2002), it is possible that loss of additional function(s) of periaxin causes the shift to myelin instability and destruction seen in Charcot-Marie-Tooth 4F (Gillespie et al., 2000). Alternatively, whereas loss of DG causes demyelination only in restricted settings (Nodari et al., 2008), binding of laminin- 2 and $\alpha$-DG by Mycobacterium leprae causes demyelination in the absence of immune cells (Rambukkana et al., 2002), suggesting that aberrant stimulation of the DGC receptor can trigger demyelination. In this light, periaxin may work as a modulator of DG function. Analysis of nerve biopsies from Charcot-Marie-Tooth $4 \mathrm{~F}$ patients carrying mutation in the $\mathrm{C}$ terminus portion of periaxin may help clarify whether demyelination is independent from the formation of compartments and reduced IL. So far, we were able to directly demonstrate that laminin-2 mutations in humans (MDC1A) lead to abnormal Schwann cell compartmentalization comparable to the mouse model of this disease.

\section{References}

Albrecht DE, Sherman DL, Brophy PJ, Froehner SC (2008) The ABCA1 cholesterol transporter associates with one of two distinct dystrophinbased scaffolds in Schwann cells. Glia 56:611-618.

Belpaire-Dethiou MC, Saito K, Fukuyama Y, Kondo-Iida E, Toda T, Duprez T, Verellen-Dumoulin C, Van den Bergh PY (1999) Congenital muscular dystrophy with central and peripheral nervous system involvement in a Belgian patient. Neuromuscul Disord 9:251-256.

Boerkoel CF, Takashima H, Stankiewicz P, Garcia CA, Leber SM, RheeMorris L, Lupski JR (2001) Periaxin mutations cause recessive DejerineSottas neuropathy. Am J Hum Genet 68:325-333.

Brill MH, Waxman SG, Moore JW, Joyner RW (1977) Conduction velocity and spike configuration in myelinated fibres: computed dependence on internode distance. J Neurol Neurosurg Psychiatry 40:769-774.

Bunge MB, Bunge RP, Pappas GD (1962) Electron microscopic demonstration of connections between glia and myelin sheaths in the developing mammalian central nervous system. J Cell Biol 12:448-453.

Colognato H, Winkelmann DA, Yurchenco PD (1999) Laminin polymerization induces a receptor-cytoskeleton network. J Cell Biol 145:619-631.

Court F, Alvarez J (2000) Nerve regeneration in Wld (s) mice is normalized by actinomycin D. Brain Res 867:1-8.

Court FA (2004) Cellular organization of peripheral nerve and the neuromuscular junction. PhD thesis, University of Edinburgh.

Court FA, Sherman DL, Pratt T, Garry EM, Ribchester RR, Cottrell DF, Fleetwood-Walker SM, Brophy PJ (2004) Restricted growth of Schwann cells lacking Cajal bands slows conduction in myelinated nerves. Nature 431:191-195.

Deconinck AE, Potter AC, Tinsley JM, Wood SJ, Vater R, Young C, Metzinger L, Vincent A, Slater CR, Davies KE (1997) Postsynaptic abnormalities at the neuromuscular junctions of utrophin-deficient mice. J Cell Biol 136:883-894.

Deodato F, Sabatelli M, Ricci E, Mercuri E, Muntoni F, Sewry C, Naom I, Tonali P, Guzzetta F (2002) Hypermyelinating neuropathy, mental retardation and epilepsy in a case of merosin deficiency. Neuromuscul Disord 12:392-398.

Di Muzio A, De Angelis MV, Di Fulvio P, Ratti A, Pizzuti A, Stuppia L, Gambi D, Uncini A (2003) Dysmyelinating sensory-motor neuropathy in merosin-deficient congenital muscular dystrophy. Muscle Nerve 27:500-506.

Feltri ML, D’Antonio M, Previtali S, Fasolini M, Messing A, Wrabetz L (1999) P0-Cre transgenic mice for inactivation of adhesion molecules in Schwann cells. Ann N Y Acad Sci 883:116-123.

Geren BB, Schmitt FO (1954) The structure of the Schwann cell and its relation to the axon in certain invertebrate nerve fibers. Proc Natl Acad Sci U S A 40:863-870.

Gillespie CS, Sherman DL, Fleetwood-Walker SM, Cottrell DF, Tait S, Garry EM, Wallace VC, Ure J, Griffiths IR, Smith A, Brophy PJ (2000) Peripheral demyelination and neuropathic pain behavior in periaxin-deficient mice. Neuron 26:523-531.

Grewal PK, Holzfeind PJ, Bittner RE, Hewitt JE (2001) Mutant glycosyltransferase and altered glycosylation of alpha-dystroglycan in the myodystrophy mouse. Nat Genet 28:151-154.

Guilbot A, Williams A, Ravisé N, Verny C, Brice A, Sherman DL, Brophy PJ, LeGuern E, Delague V, Bareil C, Mégarbané A, Claustres M (2001) A mutation in periaxin is responsible for CMT4F, an autosomal recessive form of Charcot-Marie-Tooth disease. Hum Mol Genet 10:415-421. 
Imamura M, Araishi K, Noguchi S, Ozawa E (2000) A sarcoglycandystroglycan complex anchors Dp116 and utrophin in the peripheral nervous system. Hum Mol Genet 9:3091-3100.

Jaros E, Jenkison M (1983) Quantitative studies of the abnormal axonSchwann cell relationship in the peripheral motor and sensory nerves of the dystrophic mouse. Brain Res 258:181-196.

Kidd GJ, Andrews SB, Trapp BD (1994) Organization of microtubules in myelinating Schwann cells. J Neurocytol 23:801-810.

Lane PW, Beamer TC, Myers DD (1976) Myodystrophy, a new myopathy on chromosome 8 of the mouse. J Hered 67:135-138.

Meier H, Southard JL (1970) Muscular dystrophy in the mouse caused by an allele at the dy-locus. Life Sci 9:137-144.

Michele DE, Barresi R, Kanagawa M, Saito F, Cohn RD, Satz JS, Dollar J, Nishino I, Kelley RI, Somer H, Straub V, Mathews KD, Moore SA, Campbell KP (2002) Post-translational disruption of dystroglycan-ligand interactions in congenital muscular dystrophies. Nature 418:417-422.

Mora M, Moroni I, Uziel G, di Blasi C, Barresi R, Farina L, Morandi L (1996) Mild clinical phenotype in a 12-year-old boy with partial merosin deficiency and central and peripheral nervous system abnormalities. Neuromuscul Disord 6:377-381.

Nodari A, Previtali SC, Dati G, Occhi S, Court FA, Colombelli C, Zambroni D, Dina G, Del Carro U, Campbell KP, Quattrini A, Wrabetz L, Feltri ML (2008) $\alpha 6 \beta 4$ integrin and dystroglycan cooperate to stabilize the myelin sheath. J Neurosci 28:6714-6719.

Patton BL, Miner JH, Chiu AY, Sanes JR (1997) Distribution and function of laminins in the neuromuscular system of developing, adult, and mutant mice. J Cell Biol 139:1507-1521.

Poliak S, Peles E (2003) The local differentiation of myelinated axons at nodes of Ranvier. Nat Rev Neurosci 4:968-980.

Previtali SC, Nodari A, Taveggia C, Pardini C, Dina G, Villa A, Wrabetz L, Quattrini A, Feltri ML (2003) Expression of laminin receptors in Schwann cell differentiation: evidence for distinct roles. J Neurosci 23:5520-5530.

Rambukkana A, Zanazzi G, Tapinos N, Salzer JL (2002) Contact-dependent demyelination by Mycobacterium leprae in the absence of immune cells. Science 296:927-931.

Ramón y Cajal S (1933) Histology. London: Bailliere, Tindall and Cox.

Reichl EM, Ren Y, Morphew MK, Delannoy M, Effler JC, Girard KD, Divi S, Iglesias PA, Kuo SC, Robinson DN (2008) Interactions between myosin and actin crosslinkers control cytokinesis contractility dynamics and mechanics. Curr Biol 18:471-480.

Saito F, Masaki T, Kamakura K, Anderson LV, Fujita S, Fukuta-Ohi H, Sunada Y, Shimizu T, Matsumura K (1999) Characterization of the transmembrane molecular architecture of the dystroglycan complex in schwann cells. J Biol Chem 274:8240-8246.

Saito F, Moore SA, Barresi R, Henry MD, Messing A, Ross-Barta SE, Cohn RD, Williamson RA, Sluka KA, Sherman DL, Brophy PJ, Schmelzer JD, Low PA, Wrabetz L, Feltri ML, Campbell KP (2003) Unique role of dystroglycan in peripheral nerve myelination, nodal structure, and sodium channel stabilization. Neuron 38:747-758.

Sherman DL, Brophy PJ (2005) Mechanisms of axon ensheathment and myelin growth. Nat Rev Neurosci 6:683-690.

Sherman DL, Fabrizi C, Gillespie CS, Brophy PJ (2001) Specific disruption of a schwann cell dystrophin-related protein complex in a demyelinating neuropathy. Neuron 30:677-687.

Shorer Z, Philpot J, Muntoni F, Sewry C, Dubowitz V (1995) Demyelinating peripheral neuropathy in merosin-deficient congenital muscular dystrophy. J Child Neurol 10:472-475.

Takashima H, Boerkoel CF, De Jonghe P, Ceuterick C, Martin JJ, Voit T, Schröder JM, Williams A, Brophy PJ, Timmerman V, Lupski JR (2002) Periaxin mutations cause a broad spectrum of demyelinating neuropathies. Ann Neurol 51:709-715.

Thyboll J, Kortesmaa J, Cao R, Soininen R, Wang L, Iivanainen A, Sorokin L, Risling M, Cao Y, Tryggvason K (2002) Deletion of the laminin alpha4 chain leads to impaired microvessel maturation. Mol Cell Biol 22:1194-1202.

Trapp BD, Pfeiffer SE, Anitei M, Kidd GJ (2004) Cell biology of myelin assembly. In: Myelin bioilogy and disorders, Ed 1 (Lazzarini R, ed), pp 29-48. London: Elsevier Academic.

Wallquist W, Plantman S, Thams S, Thyboll J, Kortesmaa J, Lännergren J, Domogatskaya A, Ogren SO, Risling M, Hammarberg H, Tryggvason K, Cullheim S (2005) Impeded interaction between Schwann cells and axons in the absence of laminin $\alpha 4$. J Neurosci 25:3692-3700.

Wang H, Tewari A, Einheber S, Salzer JL, Melendez-Vasquez CV (2008) Myosin II has distinct functions in PNS and CNS myelin sheath formation. J Cell Biol 182:1171-1184.

Wrabetz L, Feltri ML, Quattrini A, Imperiale D, Previtali S, D’Antonio M, Martini R, Yin X, Trapp BD, Zhou L, Chiu SY, Messing A (2000) P(0) glycoprotein overexpression causes congenital hypomyelination of peripheral nerves. J Cell Biol 148:1021-1034.

Xu H, Wu XR, Wewer UM, Engvall E (1994) Murine muscular dystrophy caused by a mutation in the laminin alpha 2 (Lama2) gene. Nat Genet 8:297-302.

Yamada H, Shimizu T, Tanaka T, Campbell KP, Matsumura K (1994) Dystroglycan is a binding protein of laminin and merosin in peripheral nerve. FEBS Lett 352:49-53.

Yamada H, Denzer AJ, Hori H, Tanaka T, Anderson LV, Fujita S, Fukuta-Ohi H, Shimizu T, Ruegg MA, Matsumura K (1996) Dystroglycan is a dual receptor for agrin and laminin-2 in Schwann cell membrane. J Biol Chem 271:23418-23423.

Yang D, Bierman J, Tarumi YS, Zhong YP, Rangwala R, Proctor TM, Miyagoe-Suzuki Y, Takeda S, Miner JH, Sherman LS, Gold BG, Patton BL (2005) Coordinate control of axon defasciculation and myelination by laminin-2 and -8. J Cell Biol 168:655-666.

Yurchenco PD, Amenta PS, Patton BL (2004) Basement membrane assembly, stability and activities observed through a developmental lens. Matrix Biol 22:521-538 